\title{
Improving Performance and Extending Lifetime of PMSMs via Advanced End-Winding Cooling
}

\author{
Vincenzo Madonna, Cosimo Spagnolo, Paolo Giangrande and Michael Galea
}

\begin{abstract}
In the automotive field, high performance and high reliable electrical machines are required and an appropriate thermal management allows to fulfil such a demand. Thermal management is also crucial for enhancing the power density, while it can also be applied to preserve the winding insulation lifetime of the electrical motor. From this prospective, an advanced cooling method is presented, whose action focuses on the end-windings, since they are commonly identified as the machine hot-spot. The effectiveness of the proposed cooling method is experimentally proven and the benefits raising from its implementation are quantified in terms of both temperature reduction, as well as insulation lifetime extension. A permanent magnet synchronous machine, employing a conventional housing water jacket is used as study-case.
\end{abstract}

Index Terms-Thermal Analysis, Cooling, Aging, Physics of Failure, Design of Experiments

\section{INTRODUCTION}

The ever increasing trend towards green transportation is driven by the transition to a post-carbon economy and the leading sectors in such paradigm shift are both aerospace and automotive fields [1-3]. In this scenario, several highly populated cities are recently switching to electrified public road transport [4]. Thus, every improvement on the electric powertrain (and in particular on the motor) might bring considerable advances at system level.

In electrical machines (EMs), the maximum allowed temperature is generally constrained by the thermal class of the adopted insulation system [5-7]. Undesired over-temperatures can compromise the drive reliability, leading to winding faults. As a rule of thumb, an over-temperature of just $10{ }^{\circ} \mathrm{C}$ halves the insulation lifetime $[8,9]$. For EMs equipped with permanent magnets (PMs), high operating temperature can cause performance degradation and eventually irreversible PMs demagnetization [10]. For these reasons, an adequate EM thermal management is a necessary requirement for guaranteeing an acceptable reliability level $[11,12]$. Lowering the winding temperature results in a reduction of the electrical resistance, which leads to lower copper losses for a given current density [13]. Conversely, a proper thermal management enables higher current density for a prescribed insulation thermal class, which results in a higher torque for the same EM size. Hence,

This work was funded by the University of Nottingham Propulsion Futures Beacon.

This work was also partially funded by the Clean Sky 2 Joint Undertaking under the European Union's Horizon 2020 research and innovation programme under grant agreement no. 821023.

V. Madonna, C. Spagnolo, P. Giangrande and M. Galea are all with the Power Electronics, Machines and Control (PEMC) group, University of Nottingham, Nottingham, NG72RD, UK (e-mail: Vincenzo.Madonna1 (a) nottingham.ac.uk). Michael Galea is also with the Key Laboratory of More Electric Aircraft Technology of Zhejiang Province, University of Nottingham Ningbo China, Ningbo 315100, China. an enhanced thermal management allows to achieve significant performance improvements in terms of both torque and power density [14].

Traditionally, low power density EMs are either natural or forced air cooled through shaft/external mounted fans [15, 16]. However, for demanding applications (i.e. high power density EMs), more effective cooling techniques can be employed [15, 17-19]. In general, forced liquid cooling methods, adopting channels, ducts or water jackets (WJs) are used. These cooling strategies aim at containing the windings temperature by transferring the heat (due to the Joule losses) to a cooling agent (e.g. water or oil) through a low thermal resistance path [17]. Thus, when forced liquid methods are installed, the winding hot-spot is then commonly located within the end-winding (EW) region [20, 21].

In order to address the issue of EW heat extraction, an innovative liquid cooling method, which directly cools the stator EW through a dedicated liquid-carrying pipe, is presented in [22]. In this work, which represent the natural continuation of [22] and [23], the proposed cooling method (PCM) is implemented on a case-study permanent magnet synchronous machine (PMSM) for traction applications. The objective is to provide a quantitative investigation on the impact that an improved EW cooling can have on the winding insulation lifetime. Using a fine-tuned lumped parameter thermal network (LPTN), the PMSM's temperature profile is assessed for standardized driving cycles. The insulation lifetime extension, arising from the PCM application, is apprised via a thermal lifetime model based on the Arrhenius-Miner's law. The developed lifetime model is calibrated relying on the findings resulting from accelerated thermal aging tests run on both motorette and coil specimens.

The paper is structured as follow: In Section II the analyzed vehicle and its requirements are introduced; Section III provides details regarding the designed PMSM; in Section IV the cooling method is briefly introduced and applied to the case-study machine through a Simulink ${ }^{\circledR}$ model; in Section V it is finally verified how the PMSM's winding insulation lifetime is affected by the overall temperature reduction.

\section{STUDY-CASE DISCUSSION}

In compliance with emission-free policy, a full-electric minivan is examined as a study-case to prove the benefits and the effectiveness of the PCM. The selected vehicle is a popular FCA Ducato Maxi 40 and its main characteristics are listed in Table I. As a preliminary step, the basic sizing of the vehicle drivetrain is carried and two standard urban drive cycles, namely ECE-15 and EUDC [24], are accounted for a fair design.

In order to evaluate the required tractive force $F_{\text {trac }}$, a standard force balance calculation is performed as reported in $(1)$, where $F_{\text {aero }}$ is the aerodynamic force, $F_{r}$ is the rolling resistance force, and $F_{\text {grade }}$ is the force necessary to overcome 
a possible road slope, whilst $m_{e q}$ is the total vehicle mass.

$$
m_{e q} \frac{d^{2} x}{d t^{2}}=F_{\text {trac }}-F_{\text {aero }}-F_{r}-F_{\text {grade }}
$$

Assuming a 5\% road slope, the load power and force against the vehicle velocity are determined, as illustrated in Fig. 1.

TABLE I

FCA DuCATo MAXI 40 - TEChNicAl Data

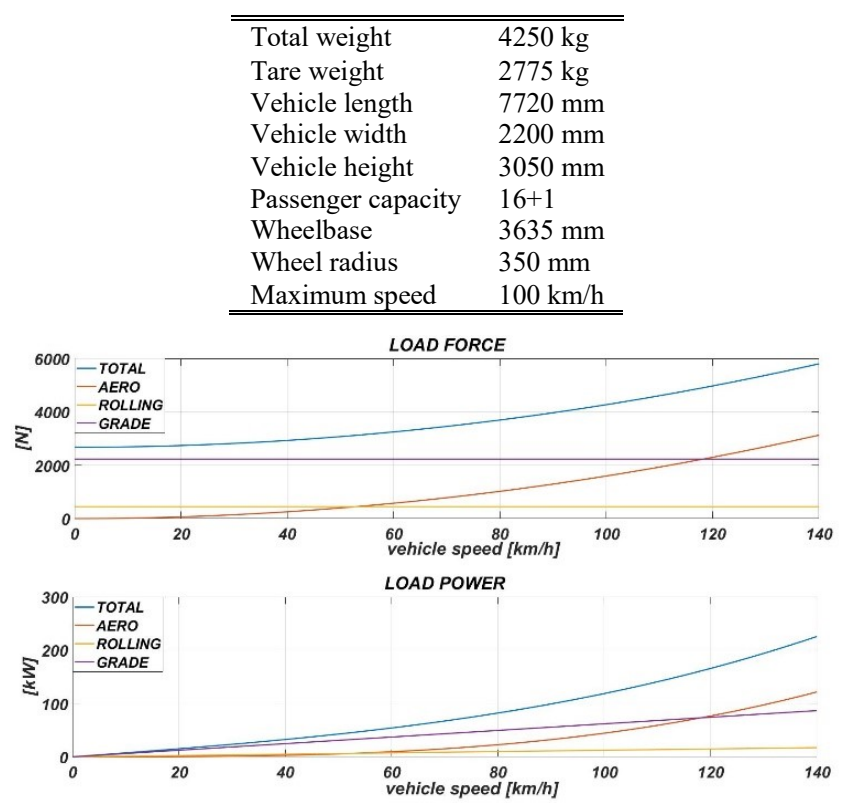

Fig. 1. Load force and power vs. speed for the considered van.

Since the minivan is not expected to exceed $100 \mathrm{~km} / \mathrm{h}$, the operating point featuring a mechanical power of $118 \mathrm{~kW}$ at $100 \mathrm{~km} / \mathrm{h}$ is chosen as baseline for the powertrain design. The demanded power is achieved by two electric motors of $78.5 \mathrm{~kW}$ each and a stepdown gearbox is placed between every motor and the wheelbase. Hence, one EM per vehicle axle is mounted because this architecture ensures an appropriate level of redundancy and availability of the entire system. The powertrain layout, together with the power distribution between the two axles, is depicted in Fig. 2.

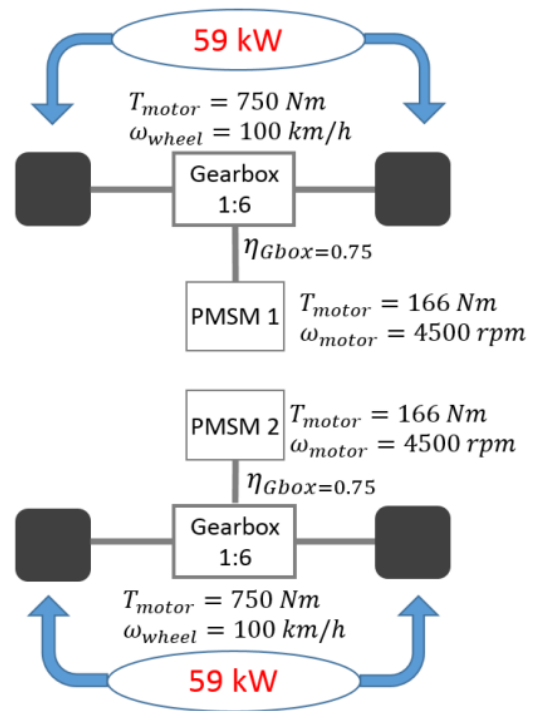

Fig. 2. Load force and power vs. speed for the considered van.

For the considered operating point, the corresponding torque $\left(T_{\text {motor }}\right)$ and speed $\left(\omega_{\text {motor }}\right)$ at the motor shaft are computed knowing that the gearbox ratio $\left(R_{\text {gear }}\right)$ is equal 6:1 and its efficiency $\left(\eta_{\text {gear }}\right)$ is conservatively supposed equal to 0.75. As a result, the single motor (i.e. PMSM 1 and PMSM 2) should develop a torque of $166 \mathrm{Nm}$ at $4500 \mathrm{rpm}$.

\section{PMSM DESIGN}

In this section, the design of the traction motor, based on the application's requirements previously calculated, is discussed. From the thermal loading point of view, it is worthy to underline that the machine will be purposely designed assuming a cooling system given by the combination of a conventional housing WJ with in addition the PCM, which acts directly on the EW. This choice reflects the cooling system implemented on the final prototype and its advantages are highlighted in both Section IV, where the PMSM thermal performance with and without PCM are compared and Section V, where the lifetime improvements associated to the adoption of the PCM are addressed.

In terms of EM topology, a PMSM is preferred to an induction machine due to its excellent power density and efficiency. Despite this choice, the PCM could be applied on either EM topologies, as it only acts on the stator EW. A trade-off study is carried out for identifying the most suitable PMs arrangement (i.e. surface mounted or interior PM). For the sake of brevity, this trade-off study is not included here, but as outcome an interior PMSM is favored. Indeed, this PMs arrangement reveals excellent overload and field weakening capabilities, where the latter feature arises from the inherent rotor's anisotropy $[25,26]$. A finite element (FE) approach is exploited for sizing and optimizing the interior PMSM and its parameters, alongside with the main geometrical dimensions are provided in Table II. The stator core is made of silicon steel (i.e. M330), while samarium-cobalt ( $\mathrm{SmCo}$ ) PMs are chosen instead of neodymium-iron-bore (NdFeB) ones, because of their superior capability in withstanding high operating temperatures [27].

TABLE II

INTERIOR PMSM DESIGN PARAMETERS

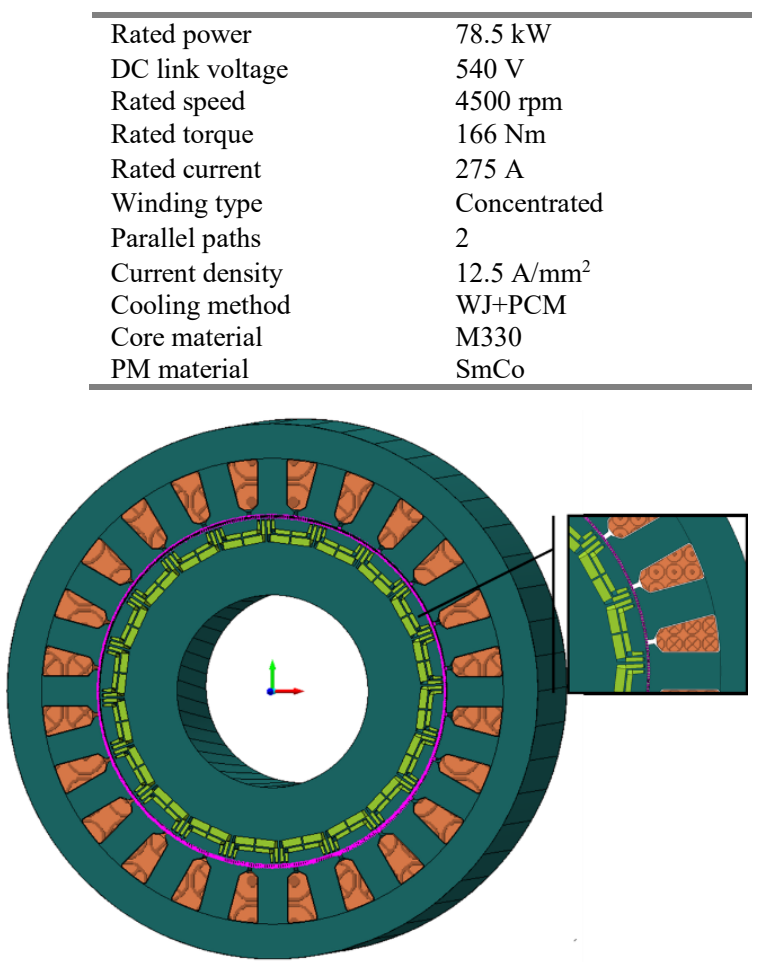

Fig. 3. 3D view of the designed interior PMSM. 
The designed interior PMSM is characterized by 24 slots and 20 poles, as shown in Fig. 3, whilst a single layer concentrated winding with two parallel paths per phase, each consisting of 9 turns, is allocated in the stator slots. The induced line-to-line back electromotive forces (back-EMFs) at $4500 \mathrm{rpm}$ are shown in Fig. 4.

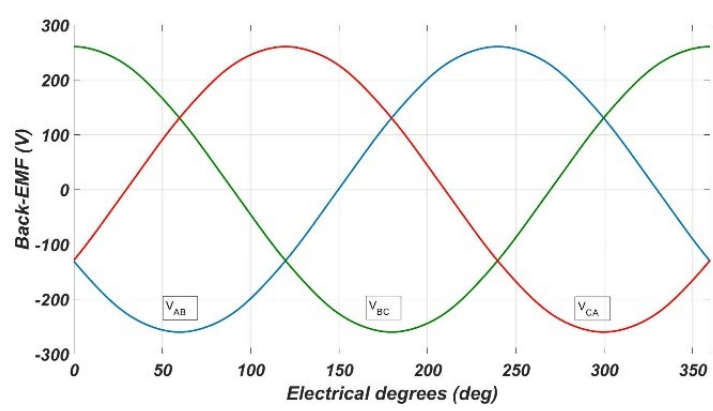

Fig. 4. Induced line-to-lined back EMFs at $4500 \mathrm{rpm}$.

The application under study requires that the developed torque is affected by a low ripple. Hence, the PMs skewing has been considered as methodology for minimizing the torque ripple [28]. In the PMSM's FE model, the PMs skewing is accounted through the multi-sliced method and by setting a PMs skewing angle of 8.5 degrees, the resulting torque ripple is equal to $3.8 \%$. In Fig. 5 , the instantaneous trend of the produced torque is reported, and its average value is $166 \mathrm{Nm}$.

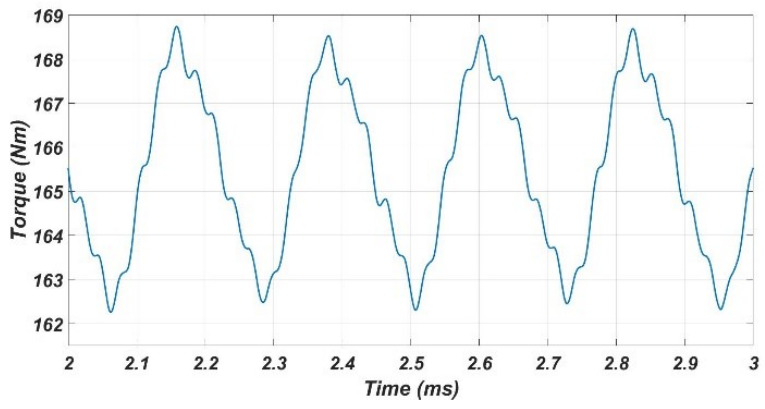

Fig. 5. Instantaneous rated torque considering the PMs skewing.

\section{CoOling Method AND Simulation RESUlts}

\section{A. Cooling method description}

A preliminary thermal analysis of the designed PMSM is performed via the commercial software MotorCad $^{\circledR}$ for verifying the temperatures distribution. When only the housing $\mathrm{WJ}$ is implemented as thermal management technique, the winding temperature hot-spot is localized in the EW region. Since temperatures above the magnet wire thermal class might significantly shorten the EM lifetime and/or lead to premature winding failures, the PCM sketched in Fig. 6 is introduced. The PCM aims at reducing the equivalent thermal resistance between the EW and the cooling liquid by directly applying a cooling pipe (CP) over the EW surface. In order to maximize the contact area between EW and $\mathrm{CP}$, the former is split in two sections (i.e. upper and lower EWs) and the CP is inserted in between. As previously mentioned, the PCM is employed in combination with the conventional housing WJ (i.e. PCM+WJ).

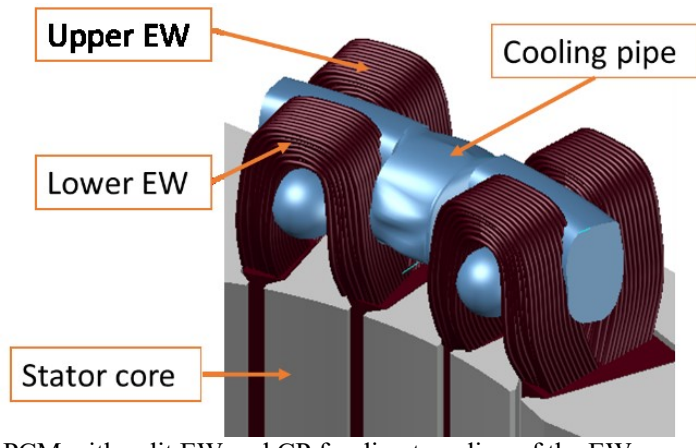

Fig. 6. PCM with split EW and CP for direct cooling of the EW.

The effectiveness of the PCM is closely related to the chosen CP material [23]. For this reason, a comparative exercise has been carried out with the purpose of determining the $\mathrm{CP}$ material that ensures the most promising thermal performance. The findings of this study are presented in [22], where several CP materials are investigated and the resulting temperatures are both predicted by means of an LPTN and measured on motorettes equipped with different CPs. The maximum temperature reduction is achieved by using silicone rubber pipe. Indeed, this material features the advantage of being very flexible and the $\mathrm{CP}$ expands when carrying pressurized fluid. Such attribute increases the contact surface between $\mathrm{EW}$ and $\mathrm{CP}$ enhancing the heat transfer.

\section{B. Driving Model and Simulation Results}

A Matlab-Simulink ${ }^{\circledR}$ model, able to simulate the whole fully-electric automotive system, is implemented. In particular, the developed model accounts for the vehicle dynamics accordingly to the data reported in Table I and the two electric drives powering the van. Two simulations based on the drive cycles ECE-15 and EUDC (i.e. vehicle speed vs. driving time) are run, where the input is represented by the speed profile and consequently the generated torque profile necessary for completing the entire cycle is obtained along with the corresponding Joule losses.

For both the tested drive cycles, the designed PMSMs are capable to deliver the demanded torque at the required speed, proving the feasibility of the full-electric solution for the FCA Ducato Maxi 40. In Figs. 7 and 8, the Joule losses generated by a single PMSM and ensuing from the application of the drive cycles ECE-15 and EUDC are respectively shown. For convenience, the Joule losses are split in two terms, namely losses occurring within the winding active length $\left(P_{S l o t}\right)$ and those inside the EWs $\left(P_{E W}\right)$.

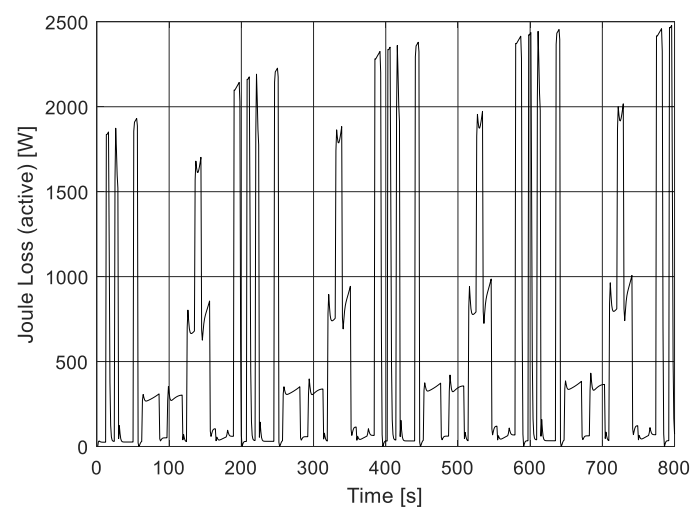

Fig. 7. Active Joule losses produced over the ECE-15 drive cycle by a single PMSM. 


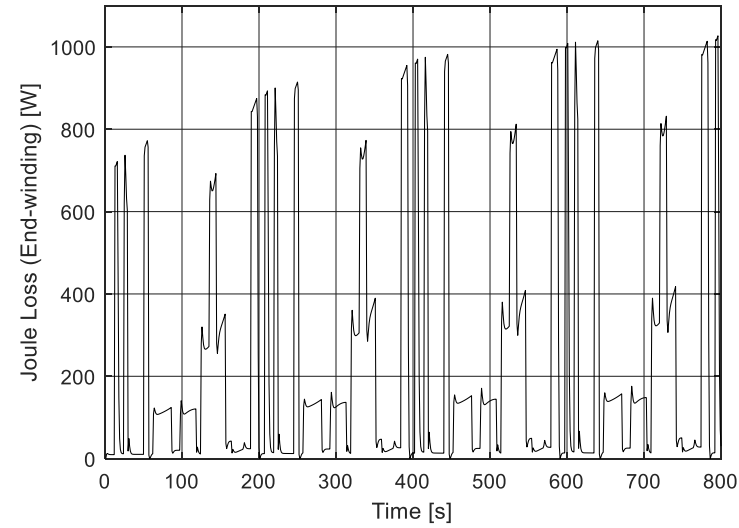

Fig. 8. Active Joule losses produced over the ECE-15 drive cycle by a single PMSM.

\section{Thermal results}

For predicting the PMSM hot-spot temperature during both drive cycles, the Joule losses profiles are applied as input to the fine-tuned LPTN shown in Fig. 9. As earlier highlighted, the PMSM thermal analysis behavior is performed considering two cooling system arrangements: 1) the sole housing WJ (i.e. no $\mathrm{CP}$ ) and 2) the combination between the $\mathrm{WJ}$ and the PCM (i.e. with CP).

The thermal resistances and capacitances included in the 7-nodes LPTN are defined in Table III. For sake of brevity, the mathematical calculation of LPTN parameters is here omitted, since it has been already detailed in [22].

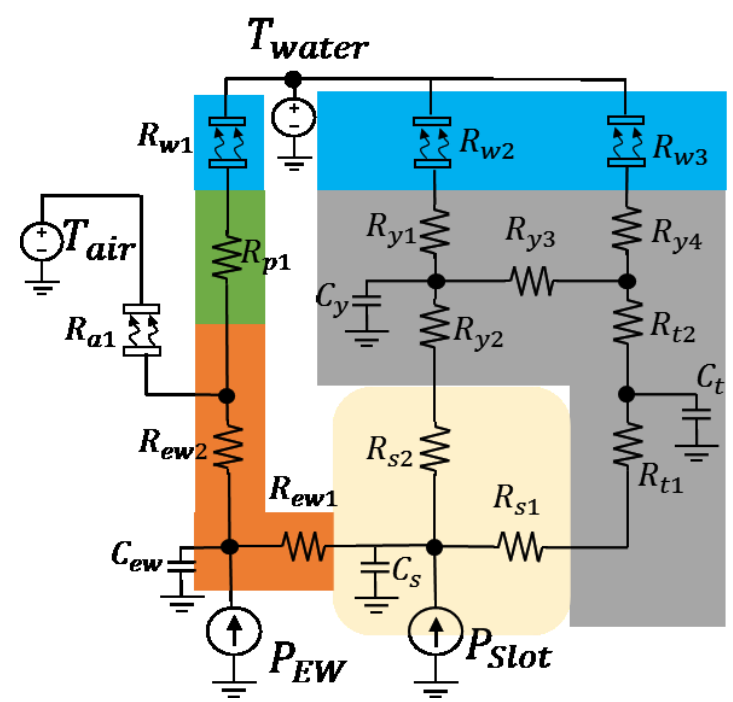

Fig. 9. 7-nodes LPTN developed for predicting the hot spot temperature.

The LPTN is fine-tuned and validated against experimental measurements, as shown in Fig. 10, where both EW and slot predicted temperatures are apprised to their measured counterparts, for various current levels. It is clearly observable that the LPTN can satisfactorily estimate the winding temperature with a $>95 \%$ accuracy.

The fine-tuned LPTN is used for evaluating the thermal performance of both cooling methods (i.e. WJ and WJ+PCM), when the two drive cycles (i.e. ECE-15 and EUDC) are accomplished by the vehicle under study. The thermal simulations examine one-hour timespan (i.e. one hour driving) and focus on the temperature rise within the PMSM's slot and EW.

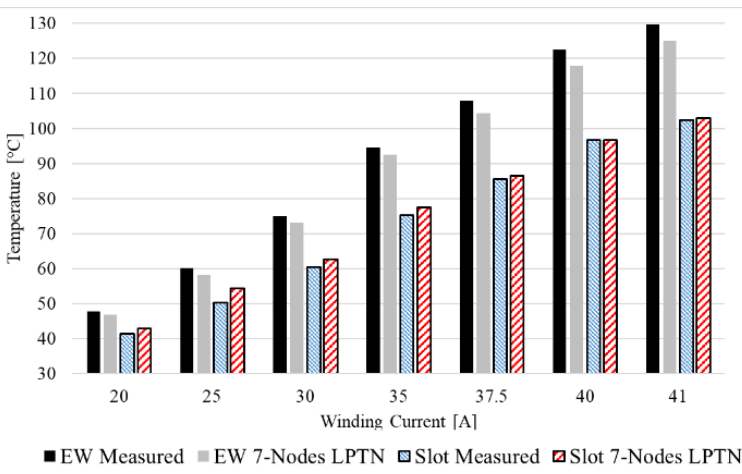

Fig. 10. LPTN validation: comparison between predicted and measured temperatures for both EW and slot.

TABLE III

Thermal Resistances (R) AND CAPACitANCES (C) UsED IN THE 7-Nodes LPTN

\begin{tabular}{ll}
\hline $\mathrm{R}_{\mathrm{s} 1}$ & Tangential slot \\
$\mathrm{R}_{\mathrm{s} 2}$ & Radial slot \\
$\mathrm{R}_{\mathrm{y} 3}$ & Tangential yoke \\
$\mathrm{R}_{\mathrm{y} 1}, \mathrm{R}_{\mathrm{y} 2} \mathrm{R}_{\mathrm{y} 4}$ & Radial yoke \\
$\mathrm{R}_{\mathrm{t} 1}, \mathrm{R}_{\mathrm{t} 2}$ & Radial tooth \\
$\mathrm{R}_{\mathrm{p} 1}$ & Pipe + Contact pipe / end-windings \\
$\mathrm{R}_{\mathrm{ew} 1}, \mathrm{R}_{\mathrm{ew} 2}$ & End-windings \\
$\mathrm{R}_{\mathrm{w} 1}$ & Pipe / Cooling fluid convection \\
$\mathrm{R}_{\mathrm{w} 2}, \mathrm{R}_{\mathrm{w} 3}$ & Water jacket / stator convection \\
$\mathrm{R}_{\mathrm{a} 1}$ & Convection end-windings / air \\
$\mathrm{C}_{\mathrm{s}}$ & Slot \\
$\mathrm{C}_{\mathrm{y}}$ & Yoke \\
$\mathrm{C}_{\mathrm{t}}$ & Tooth \\
$\mathrm{C}_{\mathrm{ew}}$ & End-windings \\
\hline
\end{tabular}

The Joule losses resulting from the Matlab-Simulink ${ }^{\circledR}$ driving model (i.e. $P_{S l o t}$ and $P_{E W}$ ) are the inputs of the LPTN and the corresponding temperature profiles are summarized in Figs. 11 and 12, for both ECE-15 and EUDC drive cycles respectively.
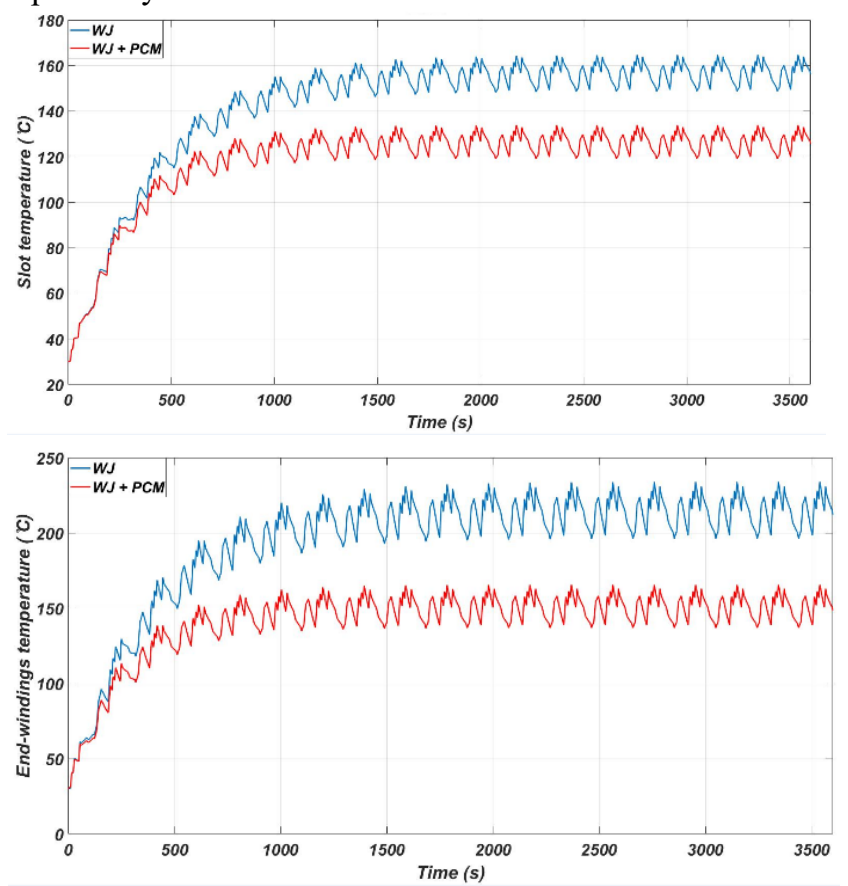

Fig. 11. Slot (top subplot) and EW (bottom subplot) temperature profiles over one hour of ECE 15 drive cycle with only WJ (blue line) and WJ+PCM (red line). 

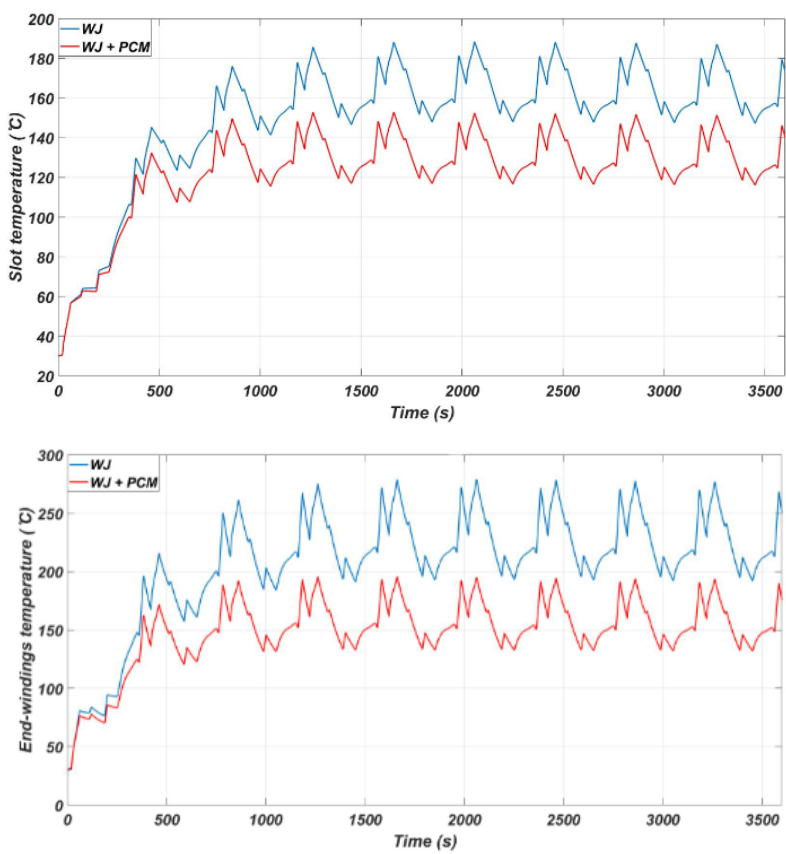

Fig. 12. Slot (top subplot) and EW (bottom subplot) temperature profiles over one hour of EUDC drive cycle with only WJ (blue line) and WJ+PCM (red line).

Analyzing the temperature within the PMSM slot, the implementation of the PCM leads to a temperature reduction compared to the cooling solution using only the housing $\mathrm{WJ}$, since an additional heat pathway is provided by the CP. In particular, the slot temperature decreases by $31^{\circ} \mathrm{C}$ in case of the ECE-15, while for the EUDC, the temperature lowering amounts to $33{ }^{\circ} \mathrm{C}$. The benefits arising for adoption of the PCM increases when the EW temperatures are considered (i.e. PMSM winding hot-spot). In fact, EW temperature drops of $64{ }^{\circ} \mathrm{C}$ and $80{ }^{\circ} \mathrm{C}$ are respectively recorded for ECE-15 and EUDC drive cycles. These results allow to conclude that the designed PMSM would not be able to always operate below the thermal limit (i.e. $200{ }^{\circ} \mathrm{C}$ ) without the insertion of the $\mathrm{CP}$ on the EW (i.e. WJ+PCM). Hence, the PMSM lifetime would be compromised if the only housing WJ is installed, as discussed in Section V.

\section{PCM AND INSULATION LIFETIME EXTENSION}

The winding hot-spot temperature reduction due to the proposed PCM, results in the possibility of increasing the winding thermal loading (i.e. current density). Alternatively, if the thermal loading is maintained, then the improved thermal management can result in an extension of the insulation lifetime. The latter aspect has been experimentally proven by performing accelerated lifetime tests on customized winding specimens.

\section{A. Specimens Choice}

The thermal simulations have shown that the hot-spot is localized in the PMSM's EW area. To identify the weakest insulation subsystem within the designed PMSM, a preliminary thermal accelerated lifetime test has been carried out on two specimens' topologies. The first one is represented by 5 motorettes, which are a scaled-down version of the PMSM stator equipped with the exact same insulating materials (i.e. liner and enameled magnet wire), as the PMSM. The second specimen topology consists in a set of 12 random-wound coils that comprise a magnet wire, whose thermal class and enamel material are identical to those of the study-case PMSM's winding. The specimen's populations (i.e. 5 motorettes and 12 random-wound coils) have been selected aiming at enhancing the statistical validity of the lifetime assessment. Both motorette and coil specimens feature a dual-strand winding layout for permitting the assessment of the inter-turn insulation conditions [29]. This winding layout is preferred because the strand-to-strand insulation is equivalent to the turn-to-turn one in low voltage, random-wound EMs.

The specimens have been thermally aged at the constant temperature of $290^{\circ} \mathrm{C}$ in a ventilated oven, as illustrated in Fig. 13. Every 8 hours, the thermal exposure is stopped and the state of the insulation subsystems is evaluated through a diagnostic session, which involves the AC hipot test. The latter is conducted with a dissipation factor tester (i.e. Megger $\left.{ }^{(}\right)$Delta 4000), which applies a voltage across the insulation subsystems. In general, the applied voltage features an amplitude above the value expected during normal operations and in the specific case, it is equal to $700 \mathrm{~V}_{\text {peak }}$ for inter-turn (i.e. strand-to-strand) insulation diagnosis for both motorettes and coils, whilst a value of $1800 \mathrm{~V}_{\text {peak }}$ is selected when the phase-to-ground insulation is apprised (only for motorettes). It is important to note that the phase-to-phase insulation subsystem is not evaluated, because the corresponding failure reveals a low probability of occurrence, due to the adoption of a non-overlapping concentrated winding.

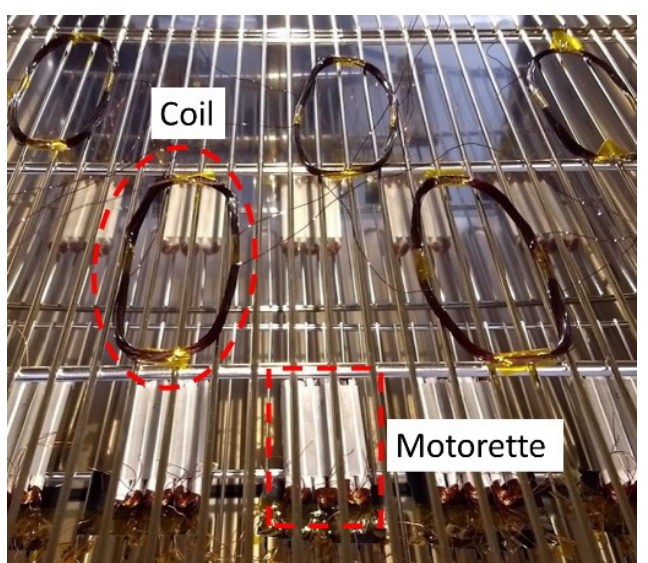

Fig. 13. Specimens during accelerated lifetime test in a ventilated oven

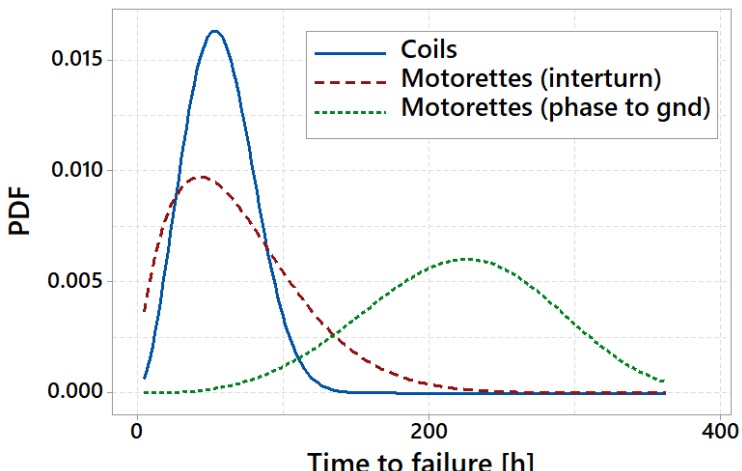

Fig. 14. Weibull PDF plot of failure times for the tested specimens at $290{ }^{\circ} \mathrm{C}$.

During the test campaign, the failure times of each specimen (i.e. the AC hipot test is not passed) are collected and Fig. 14 reports the Weibull probability density function (PDF) plot of the failure times for the inter-turn insulation (both motorettes and coils), as well as the phase-to-ground insulation (motorettes). As expected, the weakest insulation 
subsystem is represented by the inter-turn insulation. Furthermore, the coils' inter-turn insulation shows a lower median of failure time with respect to the motorettes one (i.e. 55 hours vs. 62 hours). Thus, adopting the coils as specimen for thermal lifetime prediction purposes ensures a conservative analysis.

\section{B. Insulation Lifetime Modeling}

Two additional sets of 12 random-wound coils each have been manufactured and thermally aged at as many constant temperatures. The first set is aged at $270{ }^{\circ} \mathrm{C}$, whereas $250{ }^{\circ} \mathrm{C}$ is chosen for the second set. The recorded failure times are post-processed via the two parameters Weibull distribution, and the median of failure times are extracted.

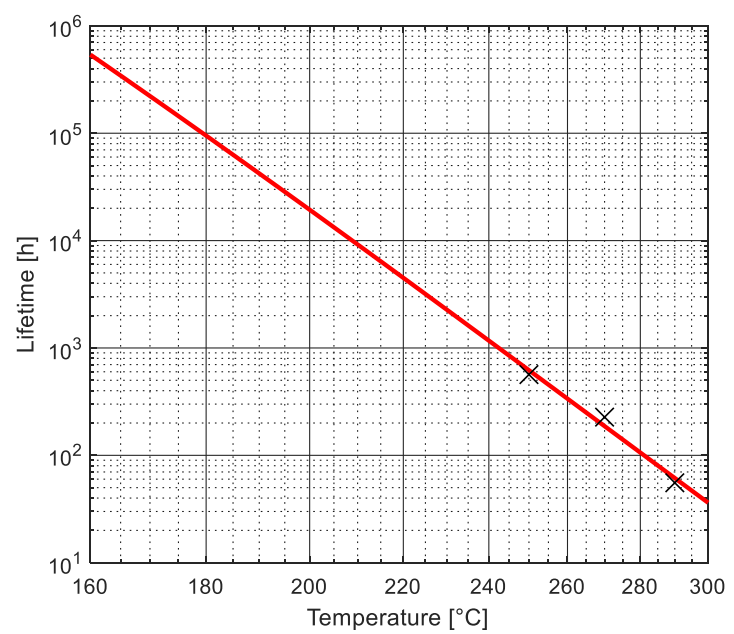

Fig. 15. Thermal endurance plot for the tested random wound coils based on the performed accelerated lifetime tests.

The outcomes of the accelerated lifetime tests on random-wound coils are used to extrapolate the thermal endurance plot (i.e. Arrhenius curve) [30], as shown in Fig. 15. This curve is described by the Arrhenius-Dakin equation $[31,32]$, which is given in (2), where $L$ is the expected insulation lifetime, $\theta$ is the absolute temperature, $A$ is the Arrhenius pre-exponential factor and $B$ is a parameter related to the activation energy of the (main) chemical reaction causing the thermal deterioration process.

$$
L(\theta)=A \cdot \exp (B / \theta)
$$

For the random-wound coils, $A$ is equal to $4.48 \cdot 10^{-12}$ hours and $B$ is equal to $17,030 \mathrm{~K}$. In order to implement the Arrhenius model for the lifetime prediction of the designed PMSM, the cumulative damage model (i.e. Miner's law) [33] is introduced as in (3), where $K$ is the number of cycles to failure, while $L F_{\text {cycle }}$ is the loss of life fraction per cycle.

$$
K=1 / L F_{\text {cycle }}
$$

$L F_{\text {cycle }}$ is expressed by (4), where $\Delta t_{\text {cycle }}$ is the time duration of a single cycle (assumed equal to 1 hour in this study) and $L\left[\theta_{i}(t)\right]$ is calculated according to (2) by assuming the instantaneous hot-spot temperature profile (cfr. Fig. 11 and 12).

$$
L F_{\text {cycle }}=\int_{0}^{\Delta t_{\text {cycle }}} d t / L\left[\left(\theta_{i}(t)\right]\right.
$$

The predicted PMSM time to failure has been determined for both the considered cooling methods (i.e. WJ and WJ+PCM), by assuming the drive cycles ECE-15 and EUDC and the obtained results are listed in Table IV. The PMSM's insulation lifetime extension ensuing from the adoption of the PCM is significantly large in both drive cycles. However, the benefit is more marked, when the PMSM works under the EUDC driving cycle, since the latter is particularly demanding in terms of thermal loading. From a reliability point of view, traction motors are generally supposed to operate reliably for at least $300,000 \mathrm{~km}$ or 10,000 hours and such lifetime requirement is surely met (with a wide safety margin) after the application of the PCM regardless the considered drive cycle.

TABLE IV

Insulation Lifetime Prediction Through ARrheniUs-Miner Model

\begin{tabular}{clc}
\hline \multirow{2}{*}{ Driving Cycle } & \multicolumn{2}{c}{ Predicted median of failure time } \\
& WJ Cooling & WJ + PCM Cooling \\
\hline ECE-15 & 7889 hours & $1.3 \cdot 10^{6}$ hours \\
EUDC & 1237 hours & $2.7 \cdot 10^{5}$ hours \\
\hline
\end{tabular}

\section{CONCLUSIONS}

In this paper, the benefits of applying an improved liquid cooling method for machines' end winding are investigated, both in terms of temperature reduction and insulation lifetime extension. A traction motor for a light commercial vehicle was considered as study-case. The preliminary sizing of the electrical machine was carried out, based on the vehicle load requirement for satisfying standard drive cycles. The thermal analysis provided evidence that relying only on the housing water jacket, the machine winding is overheated, and the insulation thermal class temperature is exceeded. This limitation was overcome by implementing the proposed cooling method, which allowed to fulfill even the most demanding drive cycle, with a hot-spot temperature drop of $80{ }^{\circ} \mathrm{C}$ in the end winding region. Finally, accelerated thermal aging tests were performed for developing an insulation lifetime prediction model according to Arrhenius-Miner's law. This model was employed for correlating the thermal improvement resulting from the implementation of the proposed cooling method with the insulation lifetime extension. In the worst-case scenario, the insulation lifetime is considerably extended by adding the end winding cooling pipe.

\section{REFERENCES}

[1] A. M. E.-. Refaie et al., "Advanced High-Power-Density Interior Permanent Magnet Motor for Traction Applications," IEEE Transactions on Industry Applications, vol. 50, no. 5, pp. 3235-3248, 2014.

[2] A. Al-Timimy et al., "Design and Losses Analysis of a High Power Density Machine for Flooded Pump Applications," IEEE Transactions on Industry Applications, vol. 54, no. 4, pp. 3260-3270, 2018.

[3] V. Madonna, G. Migliazza, P. Giangrande, E. Lorenzani, G. Buticchi, and M. Galea, "The Rebirth of the Current Source Inverter: Advantages for Aerospace Motor Design," IEEE Industrial Electronics Magazine, vol. 13 , no. 4 , pp. $65-76,2019$

[4] "Electric bus, main fleets and projects around the world. Available: https://www.sustainable-bus.com/electric-bus/electric-bus-publictransport-main-fleets-projects-around-world/," ed, 2019.

[5] V. Madonna, P. Giangrande, and M. Galea, "Evaluation of Strand-to-Strand Capacitance and Dissipation Factor in Thermally Aged Enameled Coils for Low voltage Electrical Machines," IET Science, Measurement \& Technology, vol. 13, no. 8, pp. 1170-1777, 2019.

[6] G. C. Stone, I. Culbert, E. A. Boulter, and H. Dhirani, Electrical Insulation for Rotating Machines: Design, Evaluation, Aging, Testing, and Repair. Wiley, 2014.

[7] M. Galea, P. Giangrande, V. Madonna, and G. Buticchi, "Insulation systems for electrical machines: Reliability MUST become a main 
design objective," IEEE Industrial Electronics Magazine, vol. 14, no. 1 , 2020.

[8] S. Grubic, J. M. Aller, B. Lu, and T. G. Habetler, "A Survey on Testing and Monitoring Methods for Stator Insulation Systems of Low-Voltage Induction Machines Focusing on Turn Insulation Problems," IEEE Transactions on Industrial Electronics, vol. 55, no. 12, pp. 4127-4136, 2008.

[9] V. Madonna, P. Giangrande, G. Migliazza, G. Buticchi, and M. Galea, "A Time-Saving Approach for the Thermal Lifetime Evaluation of Low Voltage Electrical Machines," IEEE Transactions on Industrial Electronics, pp. 1-1, 2019.

[10] T. Sebastian, "Temperature effects on torque production and efficiency of PM motors using NdFeB magnets," IEEE Transactions on Industry Applications, vol. 31, no. 2, pp. 353-357, 1995.

[11] C. Sciascera, P. Giangrande, L. Papini, C. Gerada, and M. Galea, "Analytical Thermal Model for Fast Stator Winding Temperature Prediction," IEEE Transactions on Industrial Electronics, vol. 64, no. 8, pp. 6116-6126, 2017.

[12] H. Zhang et al., "Thermal Model Approach to Multisector Three-Phase Electrical Machines," IEEE Transactions on Industrial Electronics, pp. $1-1,2020$.

[13] Y. Yang et al., "Thermal management of electric machines," IET Electrical Systems in Transportation, vol. 7, no. 2, pp. 104-116, 2017.

[14] M. Galea, C. Gerada, T. Raminosoa, and P. Wheeler, "A Thermal Improvement Technique for the Phase Windings of Electrical Machines," IEEE Transactions on Industry Applications, vol. 48, no. 1, pp. 79-87, 2012.

[15] W. Tong, Mechanical Design of Electric Motors. Taylor \& Francis, 2014.

[16] V. Madonna, P. Giangrande, and M. Galea, "Electrical Power Generation in Aircraft: Review, Challenges, and Opportunities," IEEE Transactions on Transportation Electrification, vol. 4, no. 3, pp. 646659, 2018.

[17] M. Popescu, D. A. Staton, A. Boglietti, A. Cavagnino, D. Hawkins, and J. Goss, "Modern Heat Extraction Systems for Power Traction Machines - A Review," IEEE Transactions on Industry Applications, vol. 52, no. 3, pp. 2167-2175, 2016.

[18] Y. Gai et al., "Cooling of Automotive Traction Motors: Schemes, Examples, and Computation Methods," IEEE Transactions on Industrial Electronics, vol. 66, no. 3, pp. 1681-1692, 2019

[19] I. Petrov, P. M. Lindh, M. Niemela, E. Scherman, O. Wallmark, and J. J. Pyrhonen, "Investigation of a Direct Liquid Cooling System in a Permanent Magnet Synchronous Machine," IEEE Transactions on Energy Conversion, pp. 1-1, 2019

[20] B. Zhang, R. Qu, J. Wang, W. Xu, X. Fan, and Y. Chen, "Thermal Model of Totally Enclosed Water-Cooled Permanent-Magnet Synchronous Machines for Electric Vehicle Application," IEEE Transactions on Industry Applications, vol. 51, no. 4, pp. 3020-3029, 2015 .
[21] P. Lindh et al., "Multidisciplinary Design of a Permanent-Magnet Traction Motor for a Hybrid Bus Taking the Load Cycle into Account," IEEE Transactions on Industrial Electronics, vol. 63, no. 6, pp. 3397 $3408,2016$.

[22] V. Madonna, A. Walker, P. Giangrande, G. Serra, C. Gerada, and M. Galea, "Improved Thermal Management and Analysis for Stator EndWindings of Electrical Machines," IEEE Transactions on Industrial Electronics, vol. 66, no. 7, pp. 5057-5069, 2019.

[23] V. Madonna, P. Giangrande, A. Walker, and M. Galea, "On the Effects of Advanced End-Winding Cooling on the Design and Performance of Electrical Machines," in 2018 XIII International Conference on Electrical Machines (ICEM), 2018, pp. 311-317.

[24] S. L. T. J. Barlow, I. S. McCrae and P. G. Boulter, "A reference book of driving cycles for use in the measurement of road vehicle emissions," (in English), Published report p. 284, 2009.

[25] S. J. Rind, Y. Ren, Y. Hu, J. Wang, and L. Jiang, "Configurations and control of traction motors for electric vehicles: A review," Chinese Journal of Electrical Engineering, vol. 3, no. 3, pp. 1-17, 2017.

[26] V. Madonna et al., "Reliability vs. Performances of Electrical Machines: Partial Discharges Issue," presented at the IEEE WEMDCD'19 - Workshop on Electrical Machines Design, Control and Diagnosis, Athens, Greece, 2019.

[27] A. Krings, M. Cossale, A. Tenconi, J. Soulard, A. Cavagnino, and A. Boglietti, "Magnetic Materials Used in Electrical Machines: A Comparison and Selection Guide for Early Machine Design," IEEE Industry Applications Magazine, vol. 23, no. 6, pp. 21-28, 2017.

[28] Z. S. Du and T. A. Lipo, "Efficient Utilization of Rare Earth PermanentMagnet Materials and Torque Ripple Reduction in Interior PermanentMagnet Machines," IEEE Transactions on Industry Applications, vol. 53, no. 4, pp. 3485-3495, 2017.

[29] V. Madonna, P. Giangrande, L. Lusuardi, A. Cavallini, C. Gerada, and M. Galea, "Thermal Overload and Insulation Aging of Short Duty Cycle, Aerospace Motors," IEEE Transactions on Industrial Electronics, vol. 67, no. 4, pp. 2618-2629, 2020.

[30] G. Turabee et al., "The Role of Neural Networks in Predicting the Thermal Life of Electrical Machines," IEEE Access, vol. 8, pp. 4028340297, 2020.

[31] T. W. Dakin, "Electrical Insulation Deterioration Treated as a Chemical Rate Phenomenon," Transactions of the American Institute of Electrical Engineers, vol. 67, no. 1, pp. 113-122, 1948.

[32] P. Giangrande, V. Madonna, S. Nuzzo, and M. Galea, "Moving Toward a Reliability-Oriented Design Approach of Low-Voltage Electrical Machines by Including Insulation Thermal Aging Considerations," IEEE Transactions on Transportation Electrification, vol. 6, no. 1, pp. $16-27,2020$.

[33] M. A. Miner, "Cumulative damage in fatigue," Journal of Applied Mechanics, vol. 12, no. 3, pp. 159-164, 1945. 